\title{
Palliative care in humanitarian crises: a review of the literature
}

\author{
Elysée Nouvet ${ }^{*}$ (D), Mollie Sivaram²${ }^{2}$, Kevin Bezanson ${ }^{3}$, Gautham Krishnaraj ${ }^{4}$, Matthew Hunt ${ }^{5}$, Sonya de Laat ${ }^{6}$, \\ Stephanie Sanger ${ }^{7}$, Laura Banfield ${ }^{7}$, Pedro Favila Escobio Rodriguez ${ }^{8}$ and Lisa J. Schwartz ${ }^{6}$
}

\begin{abstract}
This paper presents findings from a systematic review of the literature (2005-2017) on palliative care in humanitarian crises (e.g., disasters, armed conflicts, epidemics). This review set out to describe palliative care needs, practices, barriers, and recommendations in humanitarian crisis settings. It contributes to current discussions within the field of humanitarian healthcare aimed at clarifying whether or not and how best to respond to palliative care needs in humanitarian crises.

Analysis of 95 peer-reviewed and gray literature documents reveal a scarcity of data on palliative care needs and interventions provided in crises, challenges of care provision particularly due to inadequate pain relief resources and guidelines, a lack of consensus on the ethics of providing or limiting palliative care as part of humanitarian healthcare response, and the importance of contextually appropriate care. These findings suggest that more research and open discussion on palliative care in humanitarian crises are needed. This review contributes to defining palliative care needs in humanitarian crises, building consensus on humanitarian healthcare organizations' ethical responsibilities towards individuals and families with palliative needs, and developing realistic and contextappropriate policies and guidelines.
\end{abstract}

Keywords: Palliative care, End-of-life, Humanitarian healthcare, Ethics, Disaster response, Conflict, Humanitarian crisis, Low-income country (LIC) settings

\section{Introduction}

Palliative care is gaining acceptance as an important orientation for treatment in humanitarian crisis settings. A growing base of guidance and policy is developing in international aid organizations, influenced by recent examples of contexts where palliative interventions were essential in responding to patient needs. In autumn 2016, the Humanitarian Health Ethics research group in collaboration with the international group Palliative Care in Humanitarian Aid Situations \& Emergencies (PALCHASE) set out to review the literature pertaining to palliative care needs and practices in humanitarian settings. This review undertook to (1) provide detailed description of reported palliative care needs in crisis settings; (2) elucidate the values, ethics, and conditions that may limit or support the provision of palliative care by humanitarian healthcare actors; and (3) synthesize

\footnotetext{
* Correspondence: nouvete@gmail.com

${ }^{1}$ School of Health Studies, Western University, London, Canada

Full list of author information is available at the end of the article
}

recommendations on how best to integrate palliative care into humanitarian healthcare response. This review contributes to current discussions and development of recommendations within the field of humanitarian healthcare aimed at clarifying how best to respond to palliative care needs in humanitarian crises. It represents one component of a larger R2HC funded (Research for Health in Humanitarian Crises) qualitative study on palliative care in humanitarian emergencies conducted by the Humanitarian Health Ethics research group in collaboration with the Palliative Care in Humanitarian Aid Situations \& Emergencies (PALCHASE) network.

\section{Background}

The possibility and importance of integrating palliative care within humanitarian healthcare have received increased attention since 2016. A number of activities in this period have marked what appears to be an historical shift towards recognizing that palliative care needs should not be ignored within humanitarian healthcare 
response. These include the establishment in November 2016 of a World Health Organization (WHO) working group to develop guidelines for palliative care provision in humanitarian emergencies, a research colloquium on palliative care for children in humanitarian emergencies in Geneva in November 2016, the formation in August 2016 of PALCHASE (Palliative Care in Humanitarian Situations \& Emergencies) - an international network of practitioners and scholars advocating for research on and practice of palliative care in humanitarian crises, and the ongoing development of guidelines for pediatric palliative care by Médecins Sans Frontières (MSF) (Smith and Aloudat 2017) and Médecins du Monde (n.d.). The forthcoming edition of the SPHERE Handbook, if circulated drafts are an indication, will include references to palliative care needs of patients in relation to noncommunicable diseases and incorporates a new chapter on the alleviation of suffering and palliative care.

While solutions to the "problem" of unmet palliative care needs in humanitarian action are being developed, the global landscape of palliative need in humanitarian crises onto which such policies and minimum standards are being inserted remains unclear. Also unclear in current action-oriented recommendations are the values and considerations that may support or limit explicit commitments to patients' palliative care needs during humanitarian crises. This literature review seeks to address these gaps in general knowledge about palliative care in humanitarian crisis contexts. Drawing on gray and scholarly literature from 2005 to June 30, 2017, we aim to provide a snapshot of needs and practices and think about the place and practical possibility of integrating palliative care in humanitarian response. Our hope is that this literature review will help anchor policy development moving forward, while acting as a baseline of thinking about palliative care in humanitarian action in 2017 that can be re-assessed in future years.

\section{A note on our use of the term palliative care in this review} In this review, we refer to palliative care as care for all those presenting with life-limiting illness or injury, but with much greater emphasis placed on those at imminent risk of dying or identified as being at the end of life. It also includes those who require symptom control and supportive care while awaiting potentially curative medical intervention. This usage of palliative care is more specific than the WHO definition (2018), but reflects the most common applications of the term in the literature we reviewed.

\section{Methodology}

\section{Source identification and retrieval}

The review encompassed both scholarly and gray literature. We searched the following bibliographic databases for relevant English and French articles published between the years 2005 and the present: OVID MEDLINE Epub Ahead of Print, In-Process \& Other Non-Indexed Citations, OVID MEDLINE (R) Daily and OVID MEDLINE (R) 1946-Present; Embase 1974-Present; OVID PsychInfo 1806-Present; Web of Science; and CINAHL. The year 2005, as opposed to January 2007 which would allow for a more conventional 10-year date range, was used as the starting point for the literature review given that our team is particularly interested in humanitarian healthcare ethics. It is in the wake of Hurricane Katrina (September 2005) that a number of scholars began to publish on the ethical imperative of providing, or not, for palliative care needs in the aftermath of disasters worldwide.

The search strategy applied to the databases included a broad range of database appropriate subject headings: "palliative care," "disasters," "conflict," and "war," as well as additional keywords such as "terminal care" and "dying." The search strategy as used in OVID MEDLINE, including MeSH and keyword terms, can be consulted in Appendix 1. To triangulate the search, identified articles were cross-checked against findings in Proceedings First and a natural language search in Google and Google Scholar. For comprehensiveness, reference lists of relevant articles were scanned to identify supplementary citations.

To identify potentially relevant gray literature, we searched key websites that bring together resources and publications put out by humanitarian organizations (ReliefWeb and Inter-Governmental Organizations or IGO), as well as the websites of major humanitarian healthcare organizations (Table 1). Search terms for the identification of gray literature included "palliative care" or "end of life care" combined with contextual terms, including "disaster," "humanitarian aid," or "crisis."

After removal of duplicates $(N=1841)$, results were reviewed first by title and abstract, then by reading their full text, to see if they met the inclusion and exclusion criteria. The inclusion criteria required that the source discuss healthcare provision with reference to at least one humanitarian crisis in a low- and middle-income country (LMIC) and explicitly address palliative populations, patients, or care provision in such contexts. In our use of the term, humanitarian emergencies included rapid onset disasters, war and conflict settings, and public health emergencies (including epidemics). We excluded literature solely concerning disaster response in high-income countries (HIC), rehabilitative care, postdeath psychological care and family bereavement, and management of the dead. We also excluded conference abstracts, blogs, and newspaper articles. Figure 1 represents source identification methods and results progressing through the different stages of the review process. 
Table 1 Organization websites used to strengthen and triangulate gray literature search

\begin{tabular}{|c|c|}
\hline Organization & Website \\
\hline ALNAP & https://www.alnap.org \\
\hline Catholic Relief Services & https://www.crs.org \\
\hline Christian Aid & http://www.christianaid.org/home/1/home.aspx \\
\hline $\begin{array}{l}\text { International Federation } \\
\text { of Red Cross and Red } \\
\text { Crescent Societies }\end{array}$ & http://www.ifrc.org \\
\hline $\begin{array}{l}\text { International Rescue } \\
\text { Committee }\end{array}$ & https://www.rescue.org \\
\hline Médecins du Monde & www.medecinsdumonde.org/ \\
\hline MSF International & http://www.msf.org \\
\hline Save the Children & https://www.savethechildren.net \\
\hline UNHCR & http://www.unhcr.org \\
\hline UNICEF & https://www.unicef.org \\
\hline World Health Organization & http://www.who.int/en/ \\
\hline
\end{tabular}

\section{Analysis}

Sources meeting inclusion criteria were uploaded to QSR International NVivo 11.0. A preliminary coding matrix based on our key objectives formed the basis for initial, first-level coding. This codebook evolved following independent coding and comparison of article sets and identified themes by three members of the analysis team (authors 1, 2, and 6). Audit coding, to ensure accuracy and consistency, was performed by the first author (author 1), an experienced qualitative researcher. In the audit coding process, some theme names and definitions were revised. The resulting final codebook (Table 2) underlies the present synthesis.

\section{Findings}

From an initial 14,434 records, a total of 95 articles, reports, and guidelines were eventually retained for full analysis (61 from bibliographic databases, 32 from the gray literature, and two identified based on references lists of retained sources and fitting inclusion criteria). The geographical locations and types of humanitarian

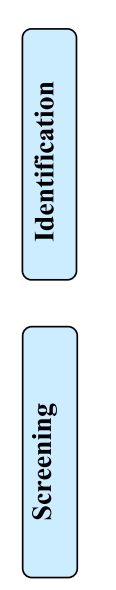

Records identified through databases: Medline $(n=3513)$; Embase $(n=5720)$; CINAHL ( $n=825)$; Psyclnfo $(n=805)$; Web of Science $(n=2818)$ $(n=13681)$
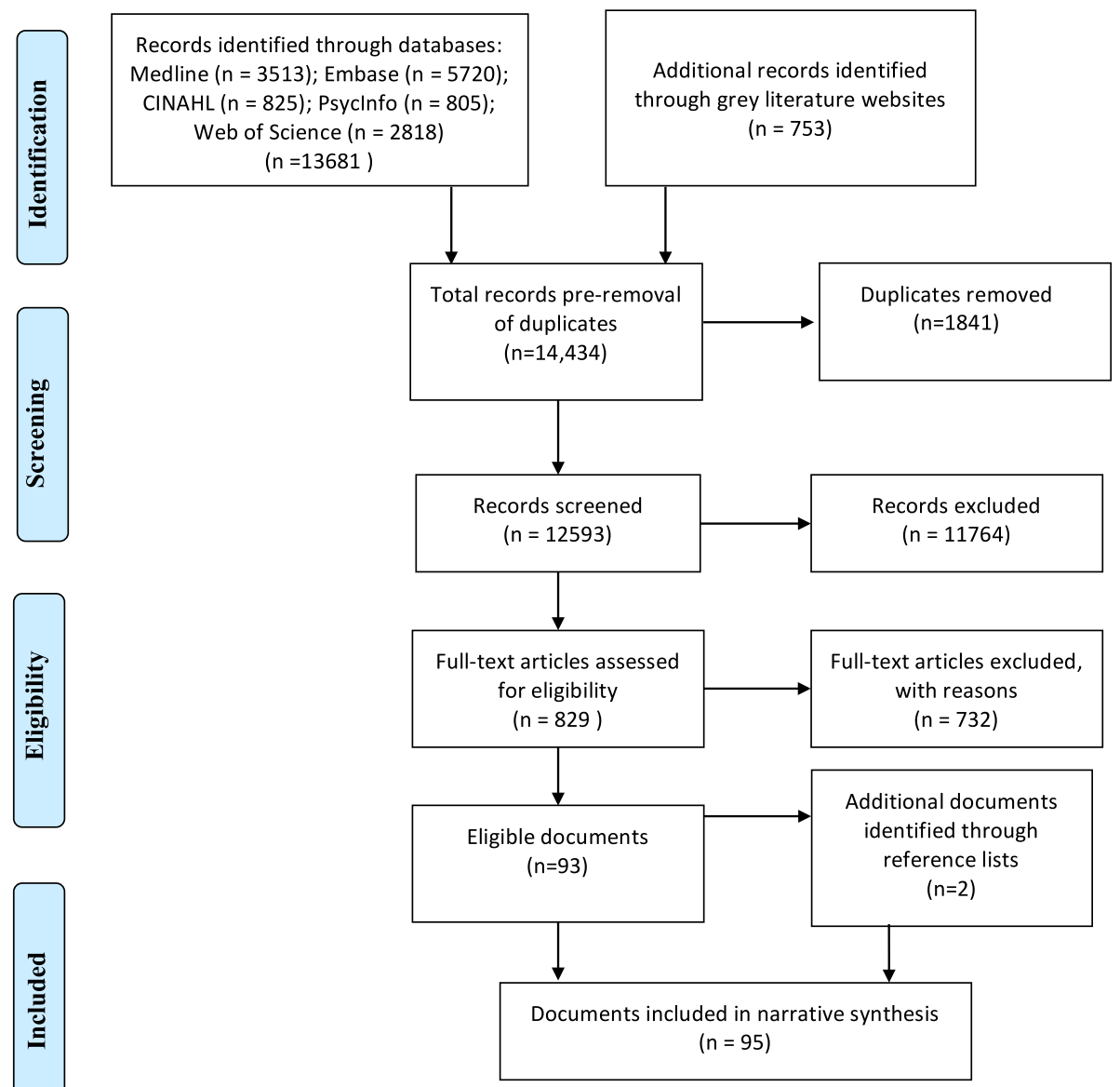

Fig. 1 Palliative care in humanitarian crises literature review flow diagram 
Table 2 Final codebook in Nvivo 11.0 organizing literature for synthesis

\begin{tabular}{|c|c|}
\hline $\begin{array}{l}\text { Key theme identified } \\
\text { in literature }\end{array}$ & Sub-theme (where applicable) \\
\hline \multicolumn{2}{|l|}{ Palliative care definitions } \\
\hline \multicolumn{2}{|c|}{ Who is defined as needing palliative care } \\
\hline \multirow[t]{7}{*}{ Current practices } & $\begin{array}{l}\text { Current palliative care training and } \\
\text { education }\end{array}$ \\
\hline & Disaster or mass casualty triage \\
\hline & Existing guidelines with limitations \\
\hline & Improvisation and flexibility \\
\hline & Lack of preparedness \\
\hline & Limited resources \\
\hline & Other challenges \\
\hline \multirow[t]{8}{*}{ Ethics or what is at stake } & Competition for resources \\
\hline & Euthanasia \\
\hline & Medical and ethical good debated \\
\hline & Rescue culture \\
\hline & Moral distress \\
\hline & Palliative care as a right \\
\hline & Palliative care as an ethical opportunity \\
\hline & Public trust \\
\hline \multirow[t]{17}{*}{ Recommendations } & $\begin{array}{l}\text { Clarify triage and palliative care } \\
\text { guidelines }\end{array}$ \\
\hline & Vulnerable populations \\
\hline & Context sensitive approach \\
\hline & Evidence-based practice \\
\hline & Imperfect ok \\
\hline & Leadership \\
\hline & Measurable impacts \\
\hline & Minimum standards \\
\hline & Training and preparedness \\
\hline & Community preparedness \\
\hline & Ethics guidance \\
\hline & Evacuation \\
\hline & Legal framework \\
\hline & Medication needs \\
\hline & Place to die \\
\hline & Support for moral distress \\
\hline & What and how to do still unclear \\
\hline
\end{tabular}

crises covered in the literature encompass a spectrum: from natural disasters such as earthquakes and tsunamis, to conflict and refugee contexts, to epidemics. Famine did not feature in any of the sources reviewed, which is striking given the high fatality rates that often result in famine contexts. In terms of patient populations in need of palliative care in crises, those (most prominently or frequently) mentioned in the literature include burn and crush victims, individuals with advanced stage kidney failure, the frail and elderly, children, individuals with life-limiting diseases such as HIV (human immune deficiency virus) or physical disabilities, and Ebola-infected individuals.

In what follows, we present a synthesis of what the literature reveals about palliative care in humanitarian crises. Drawing upon the review's initial objectives while also being responsive to what emerged in the literature, this synthesis is divided into four sections: (1) the complexity of defining palliative care needs in humanitarian crises, (2) characteristics of palliative care provision in humanitarian crises, (3) ethical rationales and potential objections to providing palliative care in humanitarian crises, and (4) recommendations for best practices of palliative care in humanitarian crises.

Part I: the complexity of defining needs for palliative care in humanitarian crises

The literature reveals a paucity of clear data on palliative care needs in humanitarian crises. Palliative care is described or recommended as part of the continuum of care for Ebola virus disease (EVD)-infected patients during the West Africa Ebola (Dhillon et al. 2015; Fowler et al. 2014; Rosoff 2015a; WHO 2016; Wolz 2014), but how often standard supportive care treatment aimed at helping patients recover from EVD became end-of-life care in Ebola Treatment Centers (ETCs) is unclear from these reports. The importance of palliative care for patients who might present for care during a humanitarian crisis affected by life-limiting and chronic conditions such as renal failure, cancers, and HIV, or other chronic noncurative conditions was also highlighted by some, but none appear to have measured-and thus none can specify - the burden, distribution, or changes to palliative care needs within such populations as a result of humanitarian crisis. What does emerge in the literature, and which may help explain this gap, are the complexities of determining and defining who needs palliative care in a humanitarian crisis. This section describes those factors that may shrink or expand needs for palliative care during a crisis, including pre- and post-disaster morbidity rates in crisis-affected populations, availability and accessibility of healthcare resources, and stage of the crisis.

\section{Impact of pre-existing and newly acquired morbidities on palliative care needs}

Categories of patients identified in the literature as being at risk of dying or likely to die and thus candidates for palliative care during a humanitarian crisis include (1) persons who were previously healthy but who became critically ill or injured by a disaster or high-fatality infectious disease; (2) individuals who prior to the crisis were highly dependent for their survival on intensive medical 
care or with pre-existing life-threatening illnesses (e.g., on ventilator, dependent on dialysis, with advanced cancer); (3) individuals in palliative and hospice care when a disaster strikes; (4) those with chronic illnesses or comorbidities whose health deteriorates as a result of a crisis; (5) individuals who require symptom control and supportive care while they await curative medical attention; and (6) any individuals likely to die when triaged out of curative medical care due to scarce resources (Bogucki and Jubanyik 2009; Cereste 2011; Huffman 2011; Martin et al. 2010; Matzo et al. 2009; Powell et al. 2017; Rosoff 2015a; Smith and Aloudat 2017; Young et al. 2017).

As this list suggests, defining palliative care needs in a given humanitarian crisis context is far from straightforward. It requires taking into account numerous factors that can increase different patient populations' vulnerability to shortened life. In many LMIC crisis settings, there may be limited or no reliable data on disease and/or who is vulnerable to dying within the crisis-affected population before or during a crisis. This gap reflects the reality that it is one thing to list the categories of individuals who might require palliative care in a crisis, and quite another to actually identify those individuals and quantify their needs in the midst of a crisis.

\section{Impact of limited resources on palliative care needs}

Limited healthcare resources can impact on curative options and palliative care provided. Committed to "population-based best opportunity for survival" (Burkle 2006), disaster and mass casualty triage have as their ethical lynchpin to "do the greatest good for the greatest number of casualties" (Biddison et al. 2014; Smith 2010). This means that where needs outpace resources, many individuals will not receive medical attention (Fossett 2013; MSF 2007; Kipnis 2013; Kuschner et al. 2007; McCullough 2010). Disaster triage, as this approach is called, goes against normative clinical ethics that aim to ensure every patient receives the best care possible (Downar et al. 2010). In settings where available resources render the provision of the best care for all ill or injured persons impossible, the triage becomes not a question of when care will be provided, but also whether or not, and for whom. As energies focus on immediate life-saving measures most likely to result in long-term survival, resources are typically diverted away from the chronically ill or otherwise vulnerable, such as the frail elderly or individuals intensely dependent on healthcare services before a disaster (Devereaux et al. 2008; Kuschner et al. 2007; Matzo et al. 2009; Powell et al. 2017; Zoraster et al. 2007; HelpAge International 2013; Inter-agency Working Group on Reproductive Health in Crises 2010; UNICEF 2015; IASC 2004; IASC 2009; WHO 2005a). At this point, no detailed quantitative or qualitative studies appear to exist quantifying the extent or impact of such norms. Towards clarifying and developing a response to unmet needs for palliative care in humanitarian crises, further documentation on the percentage of patients that might benefit from palliative care and are typically excluded or unable to access care is needed, recognizing it will vary with context and available resources.

\section{Impact of location and timing on access to and need for palliative care}

Another factor that impacts access to palliative care is proximity to health services. The location where an individual presents for post-disaster care affects whether they will be deemed treatable or palliative, and what palliative care can be allocated. Transportation of patients is often limited in a disaster setting, and what is possible for the patients based on equipment and expertise varies by location (Huffman 2011; Repine et al. 2005; Ruby et al. 2015; Fossett 2013). For example, a patient likely to survive severe injuries with ventilator support for a short period will instead be deemed palliative if there is no ventilator available (Ruby et al. 2015). Non-communicable diseases such as advanced cancer or organ failure often lack effective treatment options in these scenarios and also require palliative care. Connecting back to the issue of vulnerability, some authors note that certain individuals may become palliative due to physical or financial barriers that are amplified during a crisis, further impeding vulnerable individuals' abilities to travel and thus access healthcare (Bogucki and Jubanyik 2009; Zoraster et al. 2007). Elderly patients in need of medical attention that may include palliative care may be 'orphaned' before or after a disaster, and unable to reach the care they need without support (Golzari and Ghabili 2013).

In the context of a disaster, when an individual presents to a health care facility or clinic influences or impacts what care they are likely to receive. In some cases, it may move an individual's prognosis across the line from salvageable to non-salvageable (Rosoff 2015a). In sudden-onset disasters, what is available to a patient will also depend on the phase of the response. In the first hours following the 2010 Haiti earthquake, there was no pain medication at hand for individuals dying from crush injuries (Pou 2013). Those presenting with life-threatening illnesses or chronic illnesses unrelated to the events of the disaster during the acute phase of the response (days 0-3) may be a low priority for trauma management, but become eligible for medical attention in the sub-acute phase of the disaster (Abbasi and Salehnia 2013; Caro et al. 2011; IASC 2004; IASC 2009; Inter-agency Working Group on Reproductive Health in Crises 2010).

In summary, palliative care needs in a given crisis are contingent on pre-existing morbidities in the affected 
population, the impact of disaster on that population, available healthcare resources relative to needs, transportation, access, and the stage of the crisis. While some conditions in LMICs, such as the rapid spread of a highfatality disease as seen with Ebola in West Africa in 2014-2015, may predictably increase the need for palliative care as part of a public health emergency response, the need for palliative care in humanitarian crises is rarely so glaring. In a crisis, multiple factors may render the condition and care required for a patient more palliative in focus. Many LMIC settings lack baseline morbidity prior to a crisis, making it impossible to estimate how many more are at risk of their lives being shortened due to a crisis.

\section{Part II: characteristics of palliative care provision in humanitarian crises}

Three main characteristics of palliative care provision in humanitarian contexts stand out in the literature: this care occurs in the absence of guidelines and dedicated training, it is lived by providers as sub-optimal, and it involves improvisation or flexibility. Description of these characteristics in this section provides insights into healthcare providers' experiences of palliative care in crises and its challenges, as well as providing a basis for recommendations outlined in part IV.

\section{Lack of guidelines and training}

Guidelines and guidance documents pertaining to the provision of palliative care in humanitarian crises are limited. As we write, there is no mention of palliative or end-of-life care in key humanitarian response and disaster risk reduction guidelines such as the SPHERE Handbook and the Sendai Framework (adopted by 187 governments in 2015). Smith and Aloudat (2017) have pointed out that, "comprehensive reference to pain relief and palliative care is virtually nonexistent in most medical humanitarian guidelines (99)." While these authors flag development of such guidelines as being underway at MSF, there exist no international recommendations for the amounts of medication response teams should anticipate needing in response to a range of disasters and palliative care needs or tools for calculating such amounts (Young et al. 2017). A number of guidelines and statements, written for a range of crisis situations, recommend either palliative care or some form of symptom relief/accompaniment for patients who will not survive (Antommaria et al. 2011; Biddison et al. 2014; Caro et al. 2011; Christian et al. 2010, 2011; Devereaux et al. 2008; Jeng et al. 2014; Young et al. 2017; World Medical Association 2006; HelpAge International 2013; UNICEF 2015; WHO 2007; ICN WHO 2009; IASC 2004; IASC 2009; Inter-agency Task Team to Address HIV in Humanitarian Emergencies 2013; Inter-agency Working
Group on Reproductive Health in Crises 2010; Southern African HIV Clinicians Society/UNHCR 2007; WHO 2005a; WHO 2016), but end there. Some guidelines and articles include more specifics, such as principles for resource allocation, proposals for essential, alternative and recommended medication dosages for palliative pain relief, or suggestions for the facilities or physical locations where palliative care should be provided (Biddison et al. 2014; Caro et al. 2011; Christian et al. 2010; Downar et al. 2010; National Institute of Medicine 2009). Some guidelines and programs include home-based care (IASC 2009; Inter-agency Task Team to Address HIV in $\mathrm{Hu}$ manitarian Emergencies 2013; IFRC 2010; MSF 2011), though acknowledge that implementing such programs may be challenging during a crisis (Samuels et al. 2008). As some commentators have noted, these texts provide limited actionable guidance since they outline ideals rather than concrete recommendations for implementation (Caro et al. 2011; Pou 2013; Rosoff 2010). Two detailed review articles are exceptions: "Renal Replacement Therapy in Austere Environments" (Yuan and Perkins 2011) and, most recently, "Guidelines for Burn Care Under Austere Conditions" (Young et al. 2017). These articles might serve as models for the development of pragmatically oriented guidance for the care of other types of conditions requiring palliative care in diversely resourced scenarios.

Only one resource described pre-departure or in-field training on managing palliative care needs in humanitarian health care response, suggesting such resources are very limited. The resource we found was a new Model for Nursing Education in the United States called Cornerstone of Cultural Competency During the Disaster Cycle $\left(C^{3} \mathrm{DC}\right)$ (Danna et al. 2015). With palliative and hospice patients, as well as persons with disabilities and frail elderly in mind, it includes training on disaster preparedness for evacuation, homecare, hospice care, and symptom management (Danna et al. 2015).

Gaps in training and guidance for the realities of disaster triage contribute to a general lack of preparedness for managing palliative care needs across the humanitarian response sector. These gaps have left providers, by their own reports, scrambling ethically and practically in the midst of crises: figuring out how to allocate scarce resources such as opiates that could be used by palliative or non-palliative patients (Caro et al. 2011); explaining triage decisions to families (Pou 2013); risking litigation if administering pain relief that may hasten death (Pou 2013); and determining responsibilities in regard to patient advocacy (Goodman and Black 2015). In the absence of guidance, decisions about how to care for palliative patients are left to individual teams and providers. Documented consequences of this situation include: moral distress for providers (Baruch 2014; De 
Jong et al. 2010); lack of consensus within teams about what care to provide (Goodman and Black 2015; Huffman 2011; Pou 2013; Dhillon et al. 2015); motives for decisions being scrutinized and publicly condemned afterwards (Baruch 2014; Pou 2013: 28); and rationales for decisions remaining unclear even to the decisionmaker (Repine et al. 2005).

\section{Flexibility and improvisation}

Layered onto the lack of preparedness is the issue of scarce resources. In many LMICs, care of the dying is not a well-established practice within health systems. It may be left to families at home, or only be available in intensive care units, as has been the case until recently in Nepal (Aryal et al 2015). Many healthcare systems are also under-equipped in terms of staff, facilities, equipment, medications, and expertise, even before a humanitarian crisis occurs (Geiling et al. 2014). Shortages are exacerbated in a crisis (Samuels et al. 2008). During the Ebola crisis, oxygenation, ventilation, and hemodynamic support could not be provided for patients experiencing multisystem failure (Fowler et al. 2014). A shortage of staff combined with limitations on how long staff could be in Personal Protective Equipment (PPE) inside Ebola Treatment Centers meant patients were often unmonitored or only given care for a few minutes at a time (Danis 2015). Inevitably, such limitations impact the ability to deliver all forms of care, and certainly on psychosocial care so integral to palliation.

The issue of access to pain control medications is frequently cited as a major barrier to providing palliative care in humanitarian crises. Under non-crisis conditions, many countries already face the problem of securing and supplying opiate analgesics (Cherny 2007; International Pain Summit of the International Association for the Study of Pain 2011; Gwyther et al. 2009; Pou 2013; Rosoff 2015a). Such shortages are aggravated in emergencies. In 2012, the WHO and various humanitarian organizations called for greater support in ensuring a sustained supply of pain medications in response to the Syrian conflict (UN Department of Public Information 2016; WHO 2014). A report from the United Nations (UN) and WHO describes how civilians "cannot ... die in peace because they are not receiving necessary pain killers and palliative care that is needed in many of the besieged areas" (WHO 2016). In other situations, what some may consider less than optimal choices such as methadone or immediate release morphine may need to be used when more expensive controlled release opioid formulations are unavailable (Cherny 2007). Even where some availability exists, it may be under-used where providers are unfamiliar or uncomfortable with its usage (Allie et al. 2017), or it may be reserved to inpatient settings, making home-based palliative pain control more difficult (Rosoff 2015a). While not addressing challenges related to nationally limited supplies of pain control medications, the Model Guidelines for the International Provision of Controlled Medicines for Emergency Medical Care set out by the International Narcotics Control Board and the WHO (INCB 2011) aim to simplify the importation and exportation procedures for opioids in humanitarian crises, noting that disasters may "disrupt national drug authorities and result in them not being able to issue import licenses for controlled medicines" (WHO 2011).

A few authors provide rich descriptions of specific palliative care patients and their management in specific emergencies (Cherny 2007; Danschutter 2005; Dhillon et al. 2015; Goodman and Black 2015; Huffman 2011; Wilson 2015; Wolz 2014; Ytzhak et al. 2012). Common to these accounts is an emphasis on improvisation in the absence of specific guidance and a lack of adequate training or resources. Decision-making by the Israeli Defense Medical Corps in post-earthquake Haiti is described as a "dynamic process since not only the patient's condition changed over time, but also the surrounding medical capability changed every day, as more medical teams arrived to Port-au-Prince" (Ytzhak et al. 2012: 607). In the Palestine-Israel conflict-shaped context of Jerusalem, one patient in the final stages of cancer was initially provided with a patient-controlled analgesia (PCA) pump for home-based palliative care, but when safety concerns made regular home care staff visits impossible, the patient was successfully switched to methadone suppositories (Cherny 2007). During the West Africa Ebola outbreak, even with the challenges of PPE, many healthcare team members managed to provide psychosocial elements of palliative care such as holding hands, sitting with, and talking to patients (Wolz 2014). At one ETC, protocols established to minimize contagion risks were adapted to maximize human contact for patients likely to die. This was achieved first by allowing psychosocial teams to enter isolation units and, eventually, by even allowing family members to visit in full PPE (Wilson 2015). While such examples are clearly the exception given the limitations described above, they speak to both the needs and possibilities for palliative care provision.

\section{Part III: ethical rationales and potential objections to providing palliative care in humanitarian crises}

Those calling for the integration of palliative care into humanitarian healthcare articulate a number of ethical rationales for doing so: not providing palliative care would violate the duty to care within humanitarian healthcare (or go against the ethos of humanitarian action and medicine); providing palliative care will increase effective and fair use of scarce resources; anticipating palliative care needs can reduce moral distress for 
providers; and lack of preparedness for such care can result in morally ambiguous acts of euthanasia. These arguments and their contestations are summarized here.

Most frequent in the literature is the argument that failing to address the psychological and physical suffering of dying patients goes against the ethos of humanitarian action and medicine (Frahm et al. 2011; Marston et al. 2015; Powell et al. 2017; Rosoff 2010, 2015b; Smith and Aloudat 2017). Humanitarian actors have a duty to respond to suffering when they see it (Cherny 2007), and this includes providing palliative care where appropriate (Downar et al. 2010; Downing 2014). Life-saving measures may not be in every patient's best interest and may extend or worsen some patients' suffering (Cereste 2011). There is widespread consensus that individuals who are triaged out of rescue-oriented care must be able to expect compassionate care and symptom management (Caro et al. 2011; Gibson 2014; Powell et al. 2017; Rosoff 2015b; Southern African HIV Clinicians Society/UNHCR 2007; WHO 2007; WHO 2005a) and appropriate spaces to die that are as comfortable and culturally appropriate as possible (Downar et al. 2010; Matzo et al. 2009; Young et al. 2017).

Justice and fairness emerge in the literature as central to the ethical imperative to provide palliative care in crises. Humanitarian action has a commitment to vulnerable populations, which includes those at the end of life (Frahm et al. 2011). A goal of saving the most lives possible does not excuse discriminatory practices, such as diverting resources from the elderly on assumptions they have fewer years left (Antommaria et al. 2011). A minority of authors explicitly tie the ethical responsibility to provide palliative care in disasters to advocacy for palliative care as "a basic human right" (Fowler-Kerry and Cunningham 2010, MSF 2009). In this framing, entwined with humanitarian and clinical duties of care are the patients' rightsbased entitlements to dignity and comfort in dying.

Disaster triage guidelines which exclude from care those who cannot survive (e.g., being labeled "expectant") can be so contradictory to healthcare professional values (Burstein 2009; Cereste 2011) that they risk being applied inconsistently (Burstein 2009). If applied, ongoing lack of provider preparedness for the suffering of dying patients who do not receive care may lead to moral distress (Barilan et al. 2014; Baruch 2014; Burstein 2009; Cereste 2011; Downar et al. 2010; Caro et al. 2011; Fowler et al. 2014; Gwyther et al. 2009; Goodman and Black 2015; IRIN 2014; MSF 2014a, b, c, d, e; Powell et al. 2017). Not having any plan in place for evacuating or responding to the suffering of fragile patients may push individual providers to make choices with little support, including euthanasia of patients, as occurred during Hurricane Katrina. In that scenario, the clinical condition of patients who were euthanized remains unclear. Euthanasia occurred without patient or proxy consent and in a context where euthanasia is illegal. The general consensus in the literature we reviewed, with one exception (McCullough 2010), is that euthanasia as a means to end patient suffering during disasters is unacceptable (Biddison et al. 2014; Devereaux et al. 2008; Kuschner et al. 2007; Rosoff 2010). For these authors, the risk of such euthanasia practices alone is seen as providing a strong moral reason to better equip providers with the capacity and permission to address palliative suffering in disaster contexts (Biddison et al. 2014; Devereaux et al. 2008; Kuschner et al. 2007; Rosoff 2010).

Integrating palliative care into humanitarian healthcare response may do more harm than good, according to others. These critics do not mention the risk of moral distress. Their focus is on the exceptionality of disasters and pragmatism. In humanitarian crises, as needs typically outweigh healthcare resources, some individuals must be excluded from care (Kipnis 2013; McCullough 2010). Reflecting on the overwhelmed ETCs at the peak of the Ebola epidemic, one physician suggested that palliative care exceeded "the absolute essential" and proposed that resources and energies are better placed providing curative care and sustaining lives (Danis 2015). Clinical ethics may prescribe that health professionals aspire to the best care possible for each patient before them, but some authors argue that humanitarian crises require a distinct ethical paradigm (Kipnis 2013: 301). If enacting compassionate care for the dying means fewer resources for life saving and more fatalities, "[t]his is too high a price" (Kipnis 2013: 300; see also Danis 2015). Such critics argue that palliative care provision during crises would negatively impact others' chances at survival and hold that claims to the contrary are "unproven and counter-intuitive" (Bogucki and Jubanyik 2009).

None of the authors supporting the integration of palliative care in humanitarian healthcare propose that it would be ethical to reduce curative options where these are possible and in the patient's best interests. A response to assertions that resources are too limited in many humanitarian crises to consider palliative care is that failure to acknowledge and prepare for palliative care needs may in fact diminish, rather than support, the effective use of limited resources in such settings. Without the option of providing palliation for patients who require it, humanitarian clinicians are left with a false dichotomy (Smith and Aloudat 2017; Powell et al. 2017) of either ignoring patients' palliative care needs, or providing aggressive lifesaving treatment for patients. Should healthcare teams opt for the later (aggressive treatment over exclusion), scarce resources may be expended on care futile and burdensome to patients who might be better served by palliative interventions (Powell et al. 2017). Moreover, the suffering of such patients' may be aggravated through life-saving efforts (Powell et al. 2017). 
Many commentators are explicit that maintaining current approaches to curative care is possible alongside palliative care (Downar et al. 2010; Marston et al. 2015; Matzo et al. 2009; Rosoff 2010; Rosoff 2015c; Powell et al. 2017). Some highlight no-cost palliative care interventions: holding a patient's hand (Wolz 2014) or helping parents take on a caregiver role during their child's death (Young et al. 2017). At the same time, proponents of palliative care are not claiming commitments to palliative care in humanitarian crises should stop there. In proposing the development of a number of supports for palliative care such as wide-reaching training in basic skills and palliative care essential medicine kits (Matzo et al. 2009), it seems inevitable palliative care integration will require some additional resources (Abdel-Kader and Unruh 2009; Asgary and Jacobson 2013). While strong ethical and practical arguments are put forward for inclusion of palliative care, the impacts of enacting it on other aspects of humanitarian care and community perception remain unresolved.

\section{Part IV: recommendations for palliative care best practices in humanitarian crises}

A range of recommendations for how best to integrate palliative care in humanitarian responses has been advanced in the reviewed literature. These proposals include initiatives to develop or expand guidelines, training, resources, and the provision of culturally appropriate and sensitive end-of-life care.

Guidelines aimed at palliative care needs in humanitarian crises must first incorporate issues of triage for these contexts, as constraints and decisions may differ significantly from those in resource-rich and non-crisis settings. Existing guidelines differ in terms of who should be categorized as palliative and what resources should be allocated to or even withdrawn from these patients and re-allocated to others. These aspects have been identified as ones that require further deliberation and specification (Antommaria et al. 2011). A minority advocate for prescriptive rules on what to do for end-oflife patients and at what point palliative care should be provided (McCullough 2010; Pou 2013), but most commentators argue for a more flexible and dynamic approach: best care and fairness being contingent on available resources in a specific moment, with periodic reassessments (Caro et al. 2011; Cherny 2007; Devereaux et al. 2008; Young et al. 2017; Ytzhak et al. 2012).

Caution should be exercised in defining who is palliative and the rationales that underlie these assessments. Caro argues that triage rules should be based on evidence of likely benefit rather than assumptions of which lives are most important, for example, the young versus the old or heads of households versus single adults, unless this is done with the agreement of the affected community (Caro et al. 2011). Where families equate healthcare purely with rescue, or if mistrust of healthcare centers' intentions is widespread as was common during the West Africa Ebola outbreak (Allie et al. 2017; Downing 2014; Rosoff 2015a), provision of palliative may have negative consequences. These consequences might include fueling distrust of international responders (Fowler et al. 2014), violence against providers (Aryal et al 2015; Pou 2013), or even lawsuits once the patient dies (Nathanson 2013). To maintain trust, Matzo et al. (2009) propose that humanitarian healthcare teams be transparent in explaining when, how, why, and with what impact on resource distribution palliative care is being provided (Matzo et al. 2009).

With regards to resources, in addition to the no-cost interventions noted earlier (Downing 2014; Young et al. 2017), some recommend a portion of critical medical supplies be earmarked for palliative measures to reduce the perception of being in competition with curative efforts (Downar et al. 2010; Rosoff 2010). The need for morphine was highlighted as particularly critical to pain management for palliative patients in humanitarian crises (Danschutter 2005; Jeng et al. 2014; Marston et al. 2015). Facing significant politico-legal restrictions in many countries, some authors recommend engaging human rights mechanisms to challenge the signatories of such agreements as the International Covenant on Economic, Social, and Cultural Rights for compliance with core obligations including access to essential medicines (Gwyther et al. 2009; Smith and Aloudat 2017). Resource allocation extends beyond medications and clinical tools, and includes resources to develop educational and human resources required to deliver this care.

Several sources call for all professional disaster responders, humanitarians, and hospital staff involved in disaster management to receive at least basic training for competency in end-of-life care (Matzo et al. 2009; Powell et al. 2017; Rosoff 2010; Smith and Aloudat 2017; WHO 2016). Where all staff have such training, the onus of leadership for palliative efforts is shared widely, thus reducing the individual burden and increasing the likelihood of some baseline of palliation being provided. Many of these authors believed that this basic training should be instituted as a minimum standard (Frahm et al. 2011; Huffman 2011; Matzo et al. 2009). Others stressed the complementary value of evidence-based "on-site" training for front-line providers, to increase the palliative care capacity in disaster contexts, including sudden influxes of displaced persons (Asgary and Jacobson 2013), urban pandemic responses (Downar et al. 2010), and natural disasters (Aryal et al 2015). Including families and lay persons in these trainings may strengthen palliative capacity as some comfort care can be provided with little medical knowledge (Cherny 2007; Frahm et al. 2011; Matzo et 
al. 2009). When involving family and lay individuals as volunteers in care teams, risks to these individuals must be minimized, and ideally not be imposed (Powell 2010). Developing training on site can ensure it is culturally safe and contextually appropriate (Biddison et al. 2014).

A consideration stressed by many authors is that palliative care in humanitarian crises be culturally sensitive (Barilan et al. 2014; Biddison et al. 2014; Goodman and Black 2015; Huffman 2011; IFRC 2014; MSF 2014f; O'Laughlin and Hick 2008; WHO 2005b). This starts with triage. As Barilan et al. (2014) note, "different societies have different historical heritages and different approaches to 'tragic choices"' (p. 4). What qualifies as respectful care for the dying and dead also varies across cultures (Biddison et al. 2014; Sumathipala et al. 2006). Indeed, curative care that results in life-altering disability can also be more or less acceptable for different individuals or depending on the cultural settings (Cereste 2011). For practices to be accepted and regarded as fair, these must be clearly explained to patients and families (Aryal et al. 2015; Southern African HIV Clinicians Society/UNHCR 2007) and aligned with cultural values and personal preferences (Biddison et al. 2014; Danis 2015; Huffman 2011; O'Laughlin and Hick 2008; IFRC 2014; WHO 2005b). While recognizing the pragmatic challenges of doing so in the midst of a crisis, care plans would ideally be developed by humanitarian healthcare organizations and teams in consultation with cultural experts or community leaders within affected communities (Goodman and Black 2015).

From a research and evidence-based standpoint, there is a recognized difficulty in measuring impacts and quantifying experiences of palliative care patients in crisis settings (Danna et al. 2015; Devereaux et al. 2008; Goodman and Black 2015; Pou 2013). While many authors advocate for the expansion of research and evidence-based guidelines in this area (Matzo et al. 2009; Powell et al. 2017; Smith and Aloudat 2017), it is also proposed that all palliative care provided should be consistent with the best evidence that is available (Christian et al. 2010; Huffman 2011; Marston et al. 2015; Rosoff 2010). Relying on expert opinion or ethics committees has been identified as another helpful option when patient preferences are not known and there is no clear evidence to support one over another approach being in the patient's best interest (Antommaria et al. 2011; Ytzhak et al. 2012).

Some of the above recommendations (e.g., expanding training opportunities) require new financial investments (Abdel-Kader and Unruh 2009; Asgary and Jacobson 2013). Others may cost little, but require significant shifts in approach. Such shifts include recognizing that even those who cannot benefit from curative approaches deserve care as part of the humanitarian imperative to alleviate suffering, investing time to identify and consult with cultural experts or community leaders in affected populations to ensure contextually appropriate and culturally acceptable practices, or being transparent within teams and across the sector that palliative care may be provided at times alongside curative care in unfortunate circumstances where a curative approach is the clinical ideal.

\section{Conclusion}

Many authors over the last decade have called for better preparedness and care delivery for people who will present during crisis with non-survivable injuries, lifelimiting health conditions, or diseases. This literature review provides a snapshot of the state of these discussions in the scholarly and gray literature. It has been prepared at a time when major humanitarian actors are grappling with whether or not, how, and on what bases the provision of palliative care can and should be added into guidelines and policies for humanitarian healthcare.

Key findings include that there exists a lack of evidence beyond anecdotal accounts of palliative care needs and provision in humanitarian crises; that need for palliative care in a crisis can be hard to establish and is contingent on multiple and often shifting factors, including pre- and post-disaster morbidity rates in crisisaffected populations, availability and accessibility of healthcare resources, location, and stage of the crisis; and that palliative care that is provided typically occurs in sub-optimal conditions due to a lack of training, guidelines, and resources. There is a prevalent opinion in the literature that it is ethically and practically important for humanitarian healthcare teams to be better prepared to respond to palliative care needs. Whether or not global minimums are realistic remains to be seen given the limited resources for life-saving care in many LMIC crisis settings, and the diversity of cultural beliefs and potential preferences for end-of-life care across the globe. Also to be determined is how such minimums can be effectively and systematically implemented, funded, and evaluated.

Developing evidence-based best practices for palliative care in humanitarian crisis moving forward requires further research and evaluation of any new guidelines or programs. Epidemiological assessments of need in specific settings, clinical trials of interventions, as well as socio-anthropological studies on affected population expectations and experiences of palliative care can help clarify what resources and interventions might be most effective in specific contexts, and shed light on contextappropriate strategies for providing training and supports in palliative care for crisis settings. There is a need for detailed accounts of what care is currently being provided to palliative care patients. There is also a need for what crisis-affected populations consider feasible and acceptable palliative care in specific contexts, what ethical arguments are being advanced for expanding (or not) 
palliative care during crises, and what impact such initiatives have on patients and their families, providers, and resources in particular settings. Further discussion and debate may also be needed to build consensus on which palliative care needs should be addressed in particular crises and what policy approaches should be prioritized. Palliative care is equated with end-of-life care in most of the literature that we reviewed. Whether or not end-of-life care should be the extent of any palliative care provided in crises merits further consideration in our view.

Even if care for the dying in humanitarian emergencies is improved and recommendations adopted in the next years, complex situations will continue to arise: limited ability to predict the evolution of patient diseases that threaten life in complex and limited resources settings; the continuous rotation of health staff with different experience levels, knowledge, and perceptions of palliative care in crisis contexts, or the inability to secure minimum standardized pain relief due to political complexities of doing so. As Rosoff (2010) points out, humanitarian healthcare teams committed to providing palliative care will need to have more than one plan. There is what should be and then what could be acceptable if alternatives are needed.

\section{Appendix 1}

Strategy for Ovid Medline search

1. disasters/ or exp disaster planning/ or mass casualty incidents/ or relief work/ or rescue work/

2. Disaster Medicine/

3. ("public health" adj2 (emergenc* or crisis or crises or catastroph*)).ti,ab,kf.

4. humanitarian".mp.

5. avalanches/ or earthquakes/ or landslides/ or tidal waves/ or tsunamis/

6. cyclonic storms/ or floods/

7. (typhoon* or hurricane" or cyclon*).ti,ab,kf.

8. (avalanche* or earthquake* or flood or floods or flooding or flooded or landslide" or tsunami").ti,ab,kf.

9. exp Disease Outbreaks/

10. Ebolavirus/ or Hemorrhagic Fever, Ebola/

11. ("disease" outbreak" or pandemic" or epidemic*).ti,ab,kf.

12. ebola*.ti,ab,kf.

13. Starvation/

14. (famine* or starvation*).ti,ab,kf.

15. exp "Warfare and Armed Conflicts"/

16. (war or wars or warfare or "armed conflict"*).ti,ab,kf.

17. or $/ 1-16$

18. Palliative Care/

19. exp Terminal Care/
20. Terminally Ill/

21. ("end of life" or EOL or supportive care or lifelimiting ill* or palliative* or palliation* or critical ill*).ti,ab,kf.

22. Death/

23. Attitude to Death/

24. Health Knowledge, Attitudes, Practice/

25. exp bereavement/

26. ((terminal or endstage or end stage or advanc* stage or late stage or last stage or final stage or dying) adj5 (care* or ill" or disease* or condition* or manage*)).ti,ab,kf.

27. or $/ 18-26$

28. 17 and 27

29. limit 28 to (yr="2005 -Current" and (english or french))

\section{Abbreviations}

$C^{3} D C$ : Cornerstone of Cultural Competency During the Disaster Cycle; ETCs: Ebola Treatment Centers; EVD: Ebola virus disease; HIC: High-income countries; HIV: Human immune deficiency virus; IGO: Inter-Governmental Organizations; LMIC: Low- and middle-income countries;

PALCHASE: Palliative Care in Humanitarian Aid Situations \& Emergencies; PCA: Patient-controlled analgesia; PPE: Personal Protective Equipment; UN: United Nations; WHO: World Health Organization

\section{Acknowledgements}

The authors would like to thank our colleagues from the Palliative Care in Humanitarian Aid Situations \& Emergencies (PALCHASE) group, in particular, Joan Marston, Tony Powell, Mila Petrova, and Brett Sutton, who affirmed the need for this review and provided valuable feedback on its objectives at the outset. We would also like to thank Carrie Bernard, Lynda Redwood-Campbell, and Laurie Elit for helping us think through the ethical complexities of palliative care provision in humanitarian crises, as well as Leigh-Anne Gillespie for her invaluable help in preparing this manuscript for publication.

\section{Funding}

This article was completed as part of a larger research project on Palliative Care in Humanitarian Crises, funded by an Elrha Research for health in Humanitarian Crises (r2hc) grant (\#19775). Matthew Hunt is supported by a Research Scholar Award from the Fonds de Recherche du Québec-Santé.

\section{Availability of data and materials} N/A.

\section{Authors' contributions}

EN led the design of the review, oversaw the coding of bibliographic sources, completed an audit coding of all materials, prepared a first and all subsequent drafts, and coordinated the contributions of all co-authors. MS conducted the collection and screening of gray literature for this review, provided a synthesis of gray literature results informing the review, and drafted several paragraphs in the manuscript. KB helped design the search parameters for the review based on clinical and field experience and contributed input to strengthen all versions of the manuscript. GK provided technical support on the review of the literature from bibliographic indexes and supported the synthesis of the results. $\mathrm{MH}$ helped design the search parameters for the review and contributed input to strengthen all versions of the manuscript. SdL provided technical support on the review of the literature from bibliographic indexes and contributed input to strengthen versions of the manuscript. SS provided assistance in designing the search from bibliographic indexes, retrieved all titles from bibliographic indexes under the supervision of Laura Banfield, and drafted the methods paragraph related to this process. LB provided assistance in designing the search from bibliographic indexes and reviewed description of search methodologies for quality and comprehensiveness. PFER supported the analysis of articles related to Ebola and provided input on drafts of the manuscript. LS helped design the search parameters for the review and contributed input to strengthen all versions of the manuscript. All authors read and approved the final manuscript. 


\section{Competing interests}

The authors declare that they have no competing interests.

\section{Publisher's Note}

Springer Nature remains neutral with regard to jurisdictional claims in published maps and institutional affiliations.

\section{Author details}

${ }^{1}$ School of Health Studies, Western University, London, Canada. ${ }^{2}$ Michael G. DeGroote School of Medicine, McMaster University, Hamilton, Canada. ${ }^{3}$ Northern Ontario School of Medicine, Lakehead \& Laurentian Universities and Thunder Bay Regional Health Sciences Centre, Thunder Bay, ON, Canada. ${ }^{4}$ Humanitarian Healthcare Ethics Research Group, McMaster University, Hamilton, Canada. ${ }^{5}$ School of Physical and Occupational Therapy, McGill University, Montreal, Canada. ${ }^{6}$ Department of Health Research Methods, Evidence and Impact, McMaster University, Hamilton, Canada. ${ }^{7}$ Faculty of Health Sciences, McMaster University, Hamilton, Canada. ${ }^{8}$ Médecins du Monde, Paris, France.

\section{Received: 20 February 2018 Accepted: 27 March 2018}

\section{Published online: 20 April 2018}

\section{References}

Abbasi M, Salehnia MH (2013) Disaster medical assistance teams after earthquakes in Iran: propose a localized model. Iran Red Crescent Med J 15: 829-835. https://doi.org/10.5812/ircmj.8077

Abdel-Kader K, Unruh ML (2009) Disaster and end-stage renal disease: targeting vulnerable patients for improved outcomes. Kidney Int 75:1131-1133. https:// doi.org/10.1038/ki.2009.12

Allie MP, Colebunders R, de Clerck V, Gabaldon J (2017) MSF OCB Ebola review. MSF OCB Ebola review. Part 1: medico-operational. http://cdn.evaluation.msf. org/sites/evaluation/files/attachments/ocb_ebola_review_medop_final_2.pdf. Accessed 05 Apr 2017.

Antommaria AHM, Powell T, Miller JE, Christian MD, Task Force for Pediatric Emergency Mass Critical Care (2011) Ethical issues in pediatric emergency mass critical care. Pediatr Crit Care Med 12:S163-S168. https://doi.org/10. 1097/PCC.0b013e318234a88b

Aryal D, Acharya SP, Shrestha GS, Goffi A, Hawryluck L (2015) Nepal after the disaster: insider points of view for the future of critical care medicine. Am J Respir Crit Care Med 192:781-784. https://doi.org/10.1164/rccm.201507-1346ED

Asgary R, Jacobson K (2013) Comprehensive on-site medical and public health training for local medical practitioners in a refugee setting. Disaster Med Public Health Prep 7:82-88

Barilan YM, Brusa M, Halperin P (2014) Triage in disaster medicine: ethica strategies in various scenarios. In: Disaster bioethics: normative issues when nothing is normal. Public health ethics analysis. Springer, Dordrecht, pp 49-63 https://link.springer.com/chapter/10.1007/978-94007-3864-5_4. Accessed 25 July 2017

Baruch J (2014) Disaster response or response as disaster? Hastings Cent Rep 44: 46-47. https://doi.org/10.1002/hast.288

Biddison LD, Berkowitz KA, Courtney B et al (2014) Ethical considerations: care of the critically ill and injured during pandemics and disasters: CHEST consensus statement. Chest 146(4 Suppl):e145S-e155S. https://doi.org/10. 1378/chest.14-0742

Bogucki S, Jubanyik K (2009) Triage, rationing, and palliative care in disaster planning. Biosecur Bioterror 7:221-224. https://doi.org/10.1089/bsp.2009.0025

Burkle FM (2006) Population-based triage management in response to surgecapacity requirements during a large-scale bioevent disaster. Acad Emerg Med 13:1118-1129. https://doi.org/10.1197/j.aem.2006.06.040

Burstein JL (2009) Mostly dead: can science help with disaster triage? Ann Emerg Med 54:431. https://doi.org/10.1016/j.annemergmed.2009.02.012

Caro JJ, DeRenzo EG, Coleman NC, Weinstock DM, Knebel AR (2011) Triage and treatment tools for use in a scarce resources-crisis standards of care setting after a nuclear detonation. Disaster Med Public Health Prep 5(Supp 1):S46-S53. https://doi.org/10.1001/dmp.2011.14

Cereste HX (2011) Gray matters: a deployed physician's perspective on combat medicine in Iraq. J Relig Health 50:527-542. https://doi.org/10.1007/s10943011-9524-2

Cherny NI (2007) Palliative care in situations of conflict: lessons from Jerusalem. Am J Hosp Palliat Care 23:469-474. https://doi.org/10.1177/ 1049909106294878
Christian MD, Joynt GM, Hick JL, Colvin J, Danis M, Sprung CL (2010) Chapter 7. Critical care triage. Intensive Care Med 36:S55-S64. https://doi.org/10.1007/ s00134-010-1765-0.

Christian MD, Toltzis P, Kanter RK et al (2011) Treatment and triage recommendations for pediatric emergency mass critical care. Pediatr Crit Care Med 12:S109-S119. https://doi.org/10.1097/PCC.0b013e318234a656

Danis M (2015) Weighing the importance of palliation of symptoms for Ebola patients during the epidemic in West Africa. J Bioethics 15:70-72. https://doi. org/10.1080/15265161.2015.1011000

Danna DM, Pierce SS, Schaubhut RM, Billingsley L, Bennett MJ (2015) Educating nurses to provide culturally competent care during disasters. J Contin Educ Nurs 46:135-144. https://doi.org/10.3928/00220124-20150220-18

Danschutter DRG (2005) Tsunami: response to a disaster. Crit Care Nurs Clin North Am 17(481-494):xii. https://doi.org/10.1016/j.ccell.2005.08.005

De Jong MJ, Benner R, Benner P et al (2010) Mass casualty care in an expeditionary environment: developing local knowledge and expertise in context. J Trauma Nurs 17:45-58. https://doi.org/10.1097/JTN. Ob013e3181d914ed

Devereaux AV, Dichter JR, Christian MD et al (2008) Definitive care for the critically ill during a disaster: a framework for allocation of scarce resources in mass critical care: from a task force for mass critical care summit meeting, January 26-27, 2007, Chicago, IL. Chest 133(5 Suppl):51S-66S. https://doi.org/ 10.1378/chest.07-2693

Dhillon P, McCarthy S, Gibbs M, Sue K (2015) Palliative care conundrums in an Ebola treatment centre. BMJ Case Rep. https://doi.org/10.1136/bcr-2015-211384

Downar J, Seccareccia D, Associated Medical Services Inc. Educational Fellows in Care at the End of Life (2010) Palliating a pandemic: "all patients must be cared for.". J Pain Symptom Manag 39:291-295. https://doi.org/10.1016/j. jpainsymman.2009.11.241

Downing J (2014) Palliative nursing and the Ebola crisis. Int J Palliat Nurs 20:575. https://doi.org/10.12968/ijpn.2014.20.12.575

Fossett K (2013) Syrian attacks on health care system 'terrorising population'. Inter Press Service http://www.ipsnews.net/2013/05/syrian-attacks-on-health-caresystem-terrorising-population/. Accessed 16 Feb 2017

Fowler RA, Fletcher T, Fischer WA et al (2014) Caring for critically ill patients with Ebola virus disease: perspectives from West Africa. Am J Respir Crit Care Med 190:733-737. https://doi.org/10.1164/rccm.201408-1514CP

Fowler-Kerry S, Cunningham C (2010) Thinking about the effects of a natural disaster on existing palliative needs. Int J Palliat Nurs 16:255. https://doi.org/ 10.12968/ijpn.2010.16.5.48147

Frahm KA, Brown LM, Gibson M (2011) The importance of end-of-life care in nursing home settings is not diminished by a disaster. Omega (Westport) 64:143-155

Geiling J, Burkle FM Jr, Amundson D, Dominguez-Cherit G, Gomersall CD, Lim ML, Luyckx V, Sarani B, Uyeki TM et al (2014) Resource-poor settings: infrastructure and capacity building: care of the critically ill and injured during pandemics and disasters: CHEST consensus statement. Chest 146: e156S-e167S. https://doi.org/10.1378/chest.14-0744

Gibson M (2014) Seniors, disaster mortality, and end-of-life care. In: Disaster preparedness for seniors. Springer, New York, pp $73-87$ https://link.springer. com/chapter/10.1007/978-1-4939-0665-9_7. Accessed 25 July 2017

Golzari SEJ, Ghabili K (2013) Geriatric issues after recent twin earthquakes in Northwest Iran. J Am Geriatr Soc 61:308-309. https://doi.org/10.1111/jgs.12113

Goodman A, Black L (2015) The challenge of allocating scarce medical resources during a disaster in a low-income country: a case study from the 2010 Haitian earthquake. In: International disaster health care. Apple academic press, New York, pp 123-136. http://www.crcnetbase.com/doi/abs/10.1201/ 9781315365787-8. Accessed 25 July 2017.

Gwyther L, Brennan F, Harding R (2009) Advancing palliative care as a human right. J Pain Symptom Manag 38:767-774. https://doi.org/10.1016/j. jpainsymman.2009.03.003

HelpAge International (2013) Protection interventions for older people in emergencies.

Huffman JL (2011) Surgical palliative care in Haiti. Surg Clin North Am 91:445457. https://doi.org/10.1016/j.suc.2011.01.001

IFRC (2010) Chile: Earthquake. International Federation of Red Cross and Red Crescent Societies. (Operations Update).

IFRC (2014) Chapter 6: Culturally sensitive public Health: The HIV/AIDS disaster and beyond. http://media.ifrc.org/ifrc-pages/ifrc-responsive-footer/. Accessed 16 Feb 2017.

Inter-Agency Standing Committee (IASC) (2004) Guidelines for HIV/AIDS interventions in emergency settings. http://www.who.int/3by5/publications/ documents/en/iasc_guidelines.pdf. Accessed 16 Feb 2017 
Inter-Agency Standing Committee (IASC) (2009) Guidelines for addressing HIV in humanitarian settings. http://www.unhcr.org/protection/health/4b603d1e9/ guidelines-addressing-hiv-humanitarian-settings.html?query= palliative\%20disaster. Accessed 16 Feb 2017.

Inter-Agency Task Team to Address HIV in Humanitarian Emergencies (2013) Assessment of HIV in internally displaced situations. http://www.unhcr.org/ protection/health/53cfafb99/assessment-hiv-internally-displaced-situations. html?query=palliative\%20disaster. Accessed 16 Feb 2017.

Inter-Agency Working Group on Reproductive Health in Crises (2010) Interagency field manual on reproductive health in humanitarian settings. http:// www.who.int/reproductivehealth/publications/emergencies/field_manual/ en/. Accessed 16 Feb 2017.

International Council of Nurses (ICN), WHO Western Pacific Region (2009) ICN framework of disaster nursing competencies. http://www.wpro.who.int/hrh/ documents/icn_framework.pdf?ua=1. Accessed 16 Feb 2017.

International Nacotics Control Board (INCB) (2011). Report of the international narcotics control board on the availibility of internationally controlled drugs: ensuring adequate access for medical and scientific purposes New York: United Nations: international narcotics control board. https://www.incb.org/ documents/Publications/AnnualReports/AR2010/Supplement-AR10_ availability_English.pdf. Accessed 16 Feb 2017

International Pain Summit Of The International Association For The Study Of Pain (2011) Declaration of Montréal: declaration that access to pain management is a fundamental human right. J Pain Palliat Care Pharmacother 25:29-31. https://doi.org/10.3109/15360288.2010.547560 Accessed 16 Feb 2017

Jeng J, Gibran N, Peck M (2014) Burn care in disaster and other austere settings. Surg Clin North Am 94:893-907. https://doi.org/10.1016/j.suc.2014.05.011

Kipnis K (2013) Disasters, catastrophes, and worse: a scalar taxonomy. Camb Q Healthc Ethics 22:297-307. https://doi.org/10.1017/S096318011300011X.

Kuschner WG, Pollard JB, Ezeji-Okoye SC (2007) Ethical triage and scarce resource allocation during public health emergencies: tenets and procedures. Hosp Top 85:16-25. https://doi.org/10.3200/HTPS.85.3.16-25

Marston J, Lima LD, Powell RA (2015) Palliative care in complex humanitarian crisis responses. Lancet 386(10007):1940. https://doi.org/10.1016/S01406736(15)00825-9

Martin JE, Teff RJ, Spinella RJ (2010) Care of pediatric neurosurgical patients in Iraq in 2007: clinical and ethical experience of a field hospital. Neurosurg Pediatr 6:250-256. https://doi.org/10.3171/2010.6.PEDS1031

Matzo M, Wilkinson A, Lynn J, Gatto M, Phillips S (2009) Palliative care considerations in mass casualty events with scarce resources. Biosecur Bioterror 7:199-210. https://doi.org/10.1089/bsp.2009.0017

McCullough LB (2010) Taking seriously the "what then?" question: an ethical framework for the responsible management of medical disasters. J Clin Ethics 21:321-327

Médecins du Monde (n.d.) Pediatric palliative care: when healing is no longer possible, all is not finished. https://medecinsdumonde.ch/activites/spp/leprojet/. Accessed 16 Feb 2017

MSF (2007) Providing emergency medical care to victims of violence in the Nige Delta, Nigeria. http://www.msf.org/en/article/providing-emergency-medicalcare-victims-violence-niger-delta-nigeria. Accessed 07 Apr 2017.

MSF (2009) Adapting our practices to respect dignity. http://www.msf.ca/en/ article/adapting-our-practices-respect-dignity. Accessed 16 Feb 2017.

MSF (2011) Haiti one year after. http://www.doctorswithoutborders.org/newsstories/special-report/haiti-one-year-after. Accessed 16 Feb 2017.

MSF (2014a) Ebola: a Canadian reflects on his second mission to West Africa. http://www.msf.ca/en/article/ebola-canadian-reflects-his-second-missionwest-africa. Accessed 16 Feb 2017

MSF (2014b) "For some, Ebola is akin to magic": MSF doctors on the outbreak in West Africa. http://www.msf.ca/en/article/some-ebola-akin-magic-msfdoctors-outbreak-west-africa. Accessed 16 Feb 2017.

MSF (2014c) Global bio-disaster response urgently needed in Ebola fight. http:// reliefweb.int/report/world/global-bio-disaster-response-urgently-neededebola-fight. Accessed 16 Feb 2017.

MSF (2014d) MSF denounces international inaction on Ebola in West Africa, calls for urgent deployment of resources. http://www.msf.ca/en/article/msfdenounces-international-inaction-ebola-west-africa-calls-urgent-deploymentresources. Accessed 16 Feb 2017.

MSF (2014e) MSF international president United Nations special briefing on Ebola. http://www.msf.org/en/article/msf-international-president-united nations-special-briefing-ebola. Accessed 16 Feb 2017
MSF (2014f) "Meaningful action is needed": MSF international president Dr. Joanne Liu on Ebola. http://www.msf.ca/en/article/meaningful-action-needed-msfinternational-president-dr-joanne-liu-ebola. Accessed 16 Feb 2017.

Nathanson V (2013) Medical ethics in peacetime and wartime: the case for a better understanding. Int Rev Red Cross 95:189-213

O'Laughlin DT, Hick JL (2008) Ethical issues in resource triage. Respir Care 53:190-197

Pou AM (2013) Ethical and legal challenges in disaster medicine: are you ready? South Med J 106:27-30. https://doi.org/10.1097/SMJ.0b013e31827ca40c

Powell RA, Schwartz L, Nouvet E et al (2017) Palliative care in humanitarian crises: always something to offer. Lancet 389:1498-1499. https://doi.org/10.1016/ S0140-6736(17)30978-9

Powell T (2010) Family participation in the care of patients in public health disasters. J Clin Ethics 21:288-293

Repine TB, Lisagor P, Cohen DJ (2005) The dynamics and ethics of triage: rationing care in hard times. Mil Med 170:505-509

Rosoff PM (2010) Should palliative care be a necessity or a luxury during an overwhelming health catastrophe? J Clin Ethics 21:312-320

Rosoff PM (2015a) Caring for the suffering: meeting the Ebola crisis responsibly. Am J Bioeth 15:26-32. https://doi.org/10.1080/15265161.2015.1010995

Rosoff PM (2015b) In defense of (some) altered standards of care for Ebola infections in developed countries. HEC Forum 27:1-9. https://doi.org/10. 1007/s10730-014-9264-2.

Rosoff PM (2015c) Response to open peer commentaries on "caring for the suffering: meeting the Ebola crisis responsibly". Am J Bioeth 15:W4-W7. https://doi.org/10.1080/15265161.2015.1023116

Ruby A, Knight A, Perel P, Blanchet K, Roberts B (2015) The effectiveness of interventions for non-communicable diseases in humanitarian crises: a systematic review. PLoS One 10:e0138303. https://doi.org/10.1371/journal. pone.0138303

Samuels F, Harvey P, Bergmann T (2008) HIV and AIDS in emergency situations Overseas Development Institute. https://www.odi.org/sites/odi.org.uk/files/ odi-assets/publications-opinion-files/4277.pdf. Accessed 10 Nov 2016.

Smith J, Aloudat T (2017) Palliative care in humanitarian medicine. Palliat Med 31: 99-101. https://doi.org/10.1177/0269216316686258

Smith JS (2010) Mass casualty events: are you prepared? Nursing 40:40-45. https://doi.org/10.1097/01.NURSE.0000369865.75433.24

Southern African HIV Clinicians Society/UNHCR (2007) Clinical guidelines for antiretroviral therapy management for displaced populations southern Africa. http://www.unhcr.org/protection/health/4683b0522/clinical-guidelinesantiretroviral-therapy-management-displaced-populations.html?query= palliative\%20disaster. Accessed 10 Nov 2016.

Sumathipala A, Siribaddana S, Perera C (2006) Management of dead bodies as a component of psychosocial interventions after the tsunami: a view from Sri Lanka. Int Rev Psychiatry 18:249-257. https://doi.org/10.1080/ 09540260600656100

The Inside Story on Emergencies (IRIN) (2014) Turning away the Ebola dying http://www.irinnews.org/news/2014/09/17-1. Accessed 16 Feb 2017

UN Department of Public Information (2016) Near verbatim transcript of joint press stakeout by UN special envoy for Syria, Staffan de Mistura, UN senior advisor Jan Egeland and WHO representative in Syria Elizabeth Hoff. http:// www.unog.ch/unog/website/news_media.nsf/(httpNewsByYear_en)/EB. Accessed 1 Aug 2017.

UNICEF (2015) Newborn health in humanitarian settings (interim version). https:// www.unicef.org/videoaudio/PDFs/NewBornHealthBook-ProductionV12A.pdf. Accessed 1 Aug 2017.

WHO (2005a) Communicable disease control in emergencies: a field manual edited by M.A. Connolly. http://www.unhcr.org/protection/health/456c3ce92/ communicable-disease-control-emergencies-field-manual.html?query= palliative\%20disaster. Accessed 10 Nov 2016

WHO (2005b) Mental health of populations exposed to biological and chemical weapons. http://www.who.int/mental_health/media/bcw_and_mental_ heath who 2005.pdf?ua=1. Accessed 10 Nov 2016.

WHO (2007) Ethical considerations in developing a public health response to pandemic influenza. http://www.who.int/csr/resources/publications/WHO_ CDS_EPR_GIP_2007_2c.pdf. Accessed 10 Nov 2016.

WHO (2011) Ensuring balance in national policies on controlled substances: quidance for availability and accessibility of controlled medicines. http:/apps.who.int/iris/ bitstream/10665/44519/1/9789241564175_eng.pdf. Accessed 10 Nov 2016.

WHO (2014). World Health Organization Syrian Arab Republic annual report 2013. http://www.who.int/hac/crises/syr/syria_annual report_2103.pdf?ua=1. Accessed 10 Nov 2016. 
WHO (2016) Clinical management of patients with viral haemorrhagic fever: a pocket guide for front-line health workers: interim emergency guidance for country adaptation. http://apps.who.int/iris/bitstream/10665/205570/1/ 9789241549608_eng.pdf WHO Library Cataloguing-in-Publication Data ISBN 9789241549608 (NLM classification: WC 534. Accessed 04 May 2017 WHO (2018) WHO definition of palliative care. http://www.who.int/cancer/ palliative/definition/en/. Accessed 19 Jan 2018.

Wilson D (2015) CE: inside an Ebola treatment unit: a nurse's report. Am J Nurs 115: 28-38; quiz 39, 47. doi: https://doi.org/10.1097/01.NAJ.0000475288.30664.70.

Wolz A (2014) Face to face with Ebola - an emergency care center in Sierra Leone. New England J Med 371:1081-1083

World Medical Association (2006). Statement on medical ethics in the event of disasters. https://www.wma.net/policies-post/wma-statement-on-medicalethics-in-the-event-of-disasters/. Accessed May 12017.

Young AW, Graves C, Kowalske KJ et al (2017) Guideline for burn care under austere conditions: special care topics. J Burn Care Res 38(2):e497-e509. https://doi.org/10.1097/BCR.0000000000000369.

Ytzhak A, Sagi R, Bader T et al (2012) Pediatric ventilation in a disaster: clinical and ethical decision making. Crit Care Med 40:603-607. https://doi.org/10 1097/CCM.0b013e318232e222

Yuan CM, Perkins RM (2011) Renal replacement therapy in austere environments. Int J Nephrol 2011:1-9

Zoraster R, Vanholder R, Sever MS (2007) Disaster management of chronic dialysis patients. Am J Disaster Med 2:96-105

\section{Submit your manuscript to a SpringerOpen ${ }^{\circ}$ journal and benefit from:}

- Convenient online submission

- Rigorous peer review

- Open access: articles freely available online

- High visibility within the field

- Retaining the copyright to your article

Submit your next manuscript at $>$ springeropen.com 